\title{
Transmissivity of solar radiation within a Picea sitchensis stand under various sky conditions
}

\author{
S. Dengel ${ }^{1, a}$, J. Grace ${ }^{1}$, and A. MacArthur ${ }^{2}$ \\ ${ }^{1}$ School of GeoSciences, Crew Building, University of Edinburgh, EH9 3FF, UK \\ ${ }^{2}$ NERC Field Spectroscopy Facility (FSF), School of GeoSciences, The Grant Institute, \\ University of Edinburgh, EH9 3JW, UK \\ anow at: Department of Physics, University of Helsinki, P.O. Box 48, FI-00014 Helsinki, Finland \\ Correspondence to: S. Dengel (sigrid.dengel@helsinki.fi)
}

Received: 09 January 2015 - Published in Biogeosciences Discuss.: 27 February 2015

Revised: 17 June 2015 - Accepted: 03 July 2015 - Published: 16 July 2015

\begin{abstract}
We tested the hypothesis that diffuse radiation from cloudy and overcast skies penetrates the canopy more effectively than direct radiation from clear skies. We compared the flux density and spectral properties of direct and diffuse radiation (around solar noon $( \pm 1 \mathrm{~h})$ ) above, within and below a forest stand under sunny, cloudy and overcast conditions in a thinned Sitka spruce (Picea sitchensis (Bong.) Carr.) forest (28 years old, with a leaf area index of approximately $5.2 \mathrm{~m}^{2} \mathrm{~m}^{-2}$ ). We recorded vertical profiles of radiation penetration (from 350 to $1050 \mathrm{~nm}$ ), and we also explored the horizontal pattern of radiation along a $115 \mathrm{~m}$ transect.

We showed that in "clear sky" conditions, the photosynthetically active radiation in the lower parts of the canopy was substantially attenuated, more so than under cloudy and overcast skies. It was particularly depleted in the blue part of the spectrum, but only slightly blue-depleted when the sky was overcast or cloudy. Moreover, the red: far-red ratio under clear skies fell to values less than 0.3 but only to 0.6 under cloudy or overcast skies. Near the ground, the light climate was strongly influenced by the thinning pattern (carried out in accordance with standard forestry management practice).
\end{abstract}

\section{Introduction}

The solar radiation reaching the Earth's surface is influenced by the absorption, transmission and reflection of light by the aerosol and water vapour constituents of the atmosphere. The extent of cloud cover affects the intensity and proportions of "direct" and "diffuse" radiation reaching the Earth's surface.
While diffuse radiation is thought to enhance photosynthesis of terrestrial vegetation (Gu et al., 1999, 2002; Urban et al., 2007; Dengel and Grace, 2010), direct solar radiation can cause saturation of photosynthesis at the top of the canopy and possibly photo-inhibition (Powles, 1984; Krause, 1988; Long et al., 1994). Furthermore, unsaturated photosynthesis during direct solar radiation is possibly occurring within the canopy and understorey region as a result of shading (Kanniah et al., 2012). Urban et al. (2007, 2012) hypothesised that optimal photosynthetic activity of the canopy is achieved under diffuse radiation (cloudy) conditions, when scattered light penetrates throughout the canopy, illuminating all the leaves to some extent and providing a more uniform distribution of light between the leaves. However, the spectral properties of the diffuse component inside the canopy have only been investigated in a Norway spruce (Picea abies $L$. Karst)-European beech (Fagus sylvatica L.) forest stand in Southern Germany (Leuchner et al., 2007; Hertel et al., 2011) and a Norway spruce stand by Navrátil et al. (2007) and Urban et al. $(2007,2012)$ in the Czech Republic. No measurements are known from higher latitudes. Here, we introduce a study carried out at one out of only two Sitka spruce (Picea sitchensis (Bong.) Carr.) forest research sites in the UK and Europe where long-term forest growth and $\mathrm{CO}_{2}$ exchange measurements are carried out (Clement et al., 2003; Dengel and Grace, 2010). This species is a non-native species to the UK/Europe, but highly valued for its fast growth and timber quality. In the UK and Ireland it is the most frequently planted commercial tree species. 
The vertical profile of irradiance through a plant canopy is often approximated by the Beer-Lambert equation of light extinction first introduced by Monsi and Saeki (1953), and subsequently serves as the base of many canopy transmission studies (Grace and Woolhouse, 1973; Norman and Jarvis, 1974; Lewandowska et al., 1977; Hale, 2003; Sonohat et al., 2004). However, the equation does not describe the complexity of the radiation field to which the photosynthesising elements are exposed, neither the spatial, angular, nor the temporal distribution, because forest canopies are dynamic and far from homogenous (Gholz et al., 1991; Smith et al., 1991). The diffuse radiation inside a forest canopy includes the fraction scattered by the foliage itself as well as radiation transmitted through the leaves and through the many gaps in the foliage (Muller, 1971; Grant, 1997). Sunflecks - their size, shape, duration and spectral distribution - depend on the orientation and inclination of woody and photosynthesising elements within the forest canopy as well as the position of the sun in the sky (Federer and Tanner, 1966; Norman and Jarvis, 1974; Pearcy, 1990; Chazdon and Pearcy, 1991; Grant, 1997). The way plants respond to sunflecks may vary, and in some shade plants this response (saturation of photosynthesis, stomatal regulation or possibly photo-inhibition) may be crucial to effective gas exchange and photosynthetic production (Sellers, 1985; Leakey et al., 2003).

Indicators for light quality, in contrary to light quantity, specified for example as blue light and red : far-red ratio effects are prime factors in plant functionality. Smith (1982) indicated that the blue-absorbing photoreceptor present in plants acts to measure light quantity and that the pigment phytochrome can act to detect the red:far-red ratio as an indicator of light quality. Blue light may have important implications for stomatal control, causing stomatal opening (Morison and Jarvis, 1983), while the red:far-red ratio is known to influence photomorphogenesis, heating regulation, as well as stem elongation and chlorophyll synthesis (Gates, 1965; Smith, 1982; Wherley et al., 2005; Casal, 2013). Ritchie (1997) reported the ability of Pseudotsuga menziesii seedlings to detect the presence of nearby trees via changes in light quality and the ability to adjust their growth by altering their allometry. Low red:far-red ratio may also have implications for the adjustment to light and competition, and the optimisation of branch location in the canopy. Furthermore, Kasperbauer $(1971,1987)$ showed that row spacing and orientation (in tobacco plants) are also important regarding light quality. Leuchner et al. (2007) and Hertel et al. (2011) indicate that a reduction of the red : far-red ratio is a strong indicator for competition in Norway spruce.

The observation that diffuse light is utilised in canopy photosynthesis more effectively than direct sunlight (Urban et al., 2007; Dengel and Grace, 2010) poses a number of questions to be addressed in the present work. They are (a) to what extent is it true that light is distributed more evenly throughout the dense Sitka spruce canopy under cloudy and diffuse conditions; (b) to what extent are the light climates within the canopy spectrally different under clear, cloudy and diffuse skies and (c) how much is the light climate modified by the standard management interventions.

\section{Materials and Methods}

\subsection{Site description}

Measurements were carried out in Griffin forest (Clement et al., 2003; Clement, 2004) in Central Scotland (56 $37^{\prime} \mathrm{N}$, $3^{\circ} 48^{\prime} \mathrm{W} ; 380 \mathrm{~m}$ a.s.1.). This Sitka spruce (Picea sitchensis (Bong.) Carr.) forest was planted between 1979 and 1983 and row-thinned in 2004 by removing every fifth row of trees. In addition, trees have been felled selectively, resulting in a total of $30 \%$ of the forest stand being removed. The planting distance is around $2 \mathrm{~m}$, with approximately $11 \mathrm{~m}$ from any midthinning line to the next. The mean diameter at breast height (DBH) at the time of measurements was $37 \mathrm{~cm}$, mean canopy height $18.5 \mathrm{~m}$ and with an estimated leaf area index (LAI) of approximately $5.2 \mathrm{~m}^{2} \mathrm{~m}^{-2}$. All meteorological and micrometeorological measurements were carried out on a walk-up scaffolding tower of $22 \mathrm{~m}$ height. Below the forest canopy a $115 \mathrm{~m}$-long transect, crossing 10 sections of 1 thinned and 4 planted rows and with a North-South alignment, was established in order to measure below canopy radiation (Fig. 1).

\subsection{Methods}

\subsubsection{Spectral flux density}

Spectral distribution and flux density were measured using two spectroradiometers (GER1500, Spectra Vista, New York, USA), fitted with cosine corrected diffusers (MacArthur et al., 2012), permitting comparison of the spectral flux density (irradiant energy; units: $\mathrm{W} \mathrm{m}^{-2} \mathrm{~nm}^{-1}$ ) in the canopy with simultaneously measured spectral flux density above the canopy at $22 \mathrm{~m}$ height. The spectral resolution of the GER1500 is $3 \mathrm{~nm}$, measuring 512 channels, although the post-processing methods interpolate data to $1 \mathrm{~nm}$ intervals (Walker and MacLellan, 2009). The performance of this instrument declines in the infrared and so we restricted our measurements to the waveband $350-1050 \mathrm{~nm}$.

All spectral measurements were carried out around solar noon $( \pm 1 \mathrm{~h})$ during summer of 2008 of which 3 days are shown here as a "snapshot" (27 May, 22 July and 23 September with max solar angles of 53.5, 53.8 and $33.1^{\circ}$, respectively). These days were chosen as they show three distinctive sky conditions and a difference of approximately $600 \mu \mathrm{mol} \mathrm{m}{ }^{-2} \mathrm{~s}^{-1}$ in photosynthetic photon flux density between the measurements. Adding more days would increase the temporal distribution of the data, but at the same time it would also add a bias as measurements could not be taken in exactly the same location under the same solar radiation intensity. The solar spectrum has a pronounced diurnal variation and so we carried out measurements at midday. Tower 


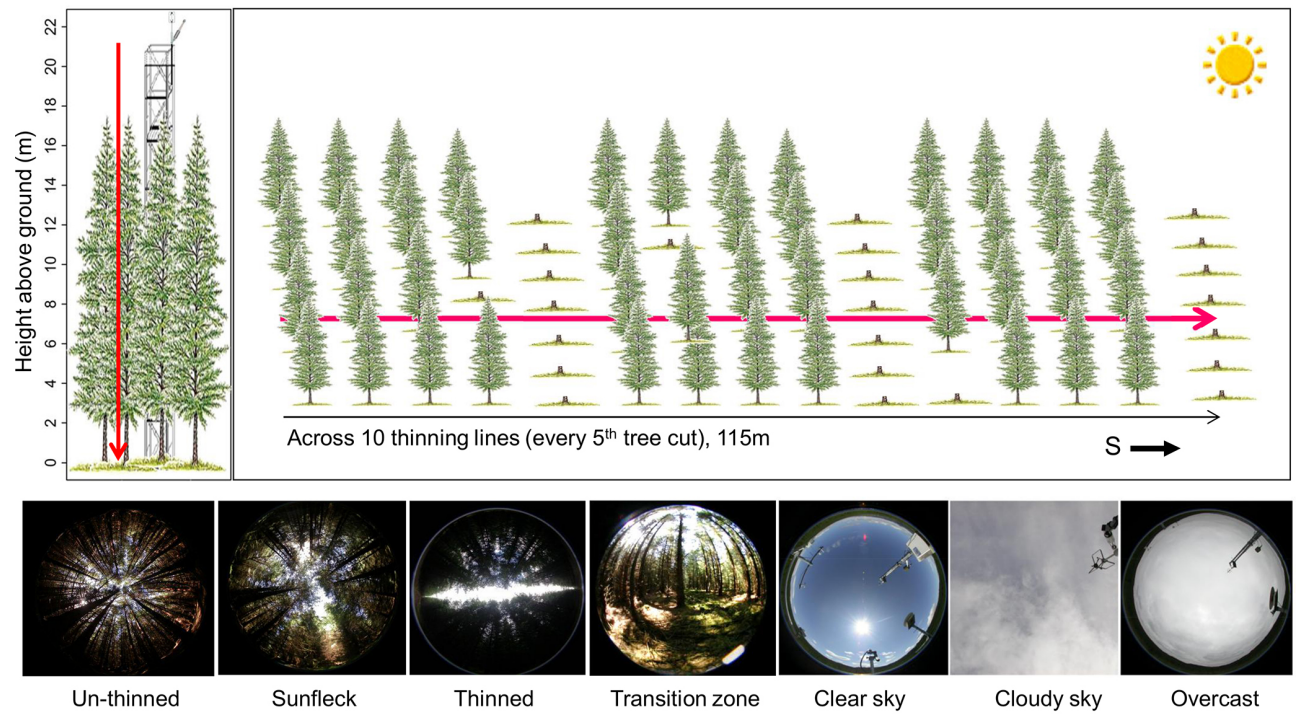

Figure 1. Schematics of the Griffin forest planting and tree distribution properties, showing the thinning lines (the stumps are illustrated). Also shown are hemispherical images taken in the un-thinned as well as thinned area of the forest.

and forest floor (transect) scans were carried out back-toback within less than $10 \mathrm{~min}$ of each other. One complete set of measurements including the vertical and horizontal measurements took around $1 \mathrm{~h}$. Vertical profiles of radiation penetrating the canopy were made by taking three measurements at $1 \mathrm{~m}$ intervals $1.5 \mathrm{~m}$ from the tower (south facing, opposite side of the artificial gap created during the tower installation), while the scans recorded for evaluation of the horizontal variation were measured at $1 \mathrm{~m}$ height with $2.5 \mathrm{~m}$ intervals along a transect. Three measurements were carried out at each point of which each measurement represents an average of 10 internally averaged scans. Measurements were carried out under (i) clear sky conditions (clearness index of around 0.75 over the measurement period), (ii) cloudy conditions (we selected conditions with altostratus clouds to guarantee minimal changes in cloudiness over the measurement period (clearness index of 0.60) and (iii) on a completely overcast day (clearness index of 0.23 ). In all cases, light conditions above the forest canopy did not change significantly over the measuring period. The spectral distribution of the incoming solar radiation also did not show any significant differences as can be seen in Fig. 2a and b. To facilitate comparison, data were normalised to the range 0 to 1 where appropriate. In order to scale the data we have applied the following scaling method:

$\mathrm{ND}_{i}=\frac{x_{i}-\min (x)}{\max (x)-\min (x)}$,

where $x=\left(x_{1}, \ldots, x_{n}\right)$ and $\mathrm{ND}_{i}$ is the $i$ th normalised data.

\subsubsection{Leaf area index}

The vertical distribution of leaf area index (LAI) was estimated from hemispherical images taken every $2 \mathrm{~m}$ down the tower using a Nikon digital camera (Coolpix 4500, Nikon Corporation, Tokyo, Japan) with a fish-eye lens attachment (Fish-eye converter FC-E8, Nikon Corporation, Tokyo, Japan). Images were acquired following the protocols established by Chen et al. (1997a, b) and van Gardingen et al. (1999), and were processed with the scientific image processing software Gap Light Analyzer (GLA) (Forest Renewal BC, Frazer et al., 1999). Images were taken along the same path as the spectral measurements (southfacing, opposite side from the artificial gap/thinning line), halved and mirrored in order to avoid tower structural elements being recorded as part of the canopy. When calculating LAI from hemispherical images in coniferous forests, a correction value, known as the clumping index (van Gardingen et al., 1999), is necessary to account for structural aspects of the canopy. The necessary clumping index value has been calculated from several transect measurements, using a TRAC (Tracing the Radiation and Architecture of Canopies, Leblanc et al. (2002) (3rd Wave Engineering, Nepean, Canada) in Griffin forest during the growing season of 2007 and 2008 and was found to be 0.98 . A detailed explanation on the use of this instrument is given in Sect. 2.2.4.

\subsubsection{Photosynthetic photon flux density and transmissivity at various wavelengths}

Values of photosynthetic photon flux density (PPFD) were calculated by converting irradiant energy $\left(\mathrm{W} \mathrm{m}^{-2} \mathrm{~nm}^{-1}\right.$ ) to quanta $\left(\mu \mathrm{mol} \mathrm{m}{ }^{-2} \mathrm{~s}^{-1}\right.$ ) and integrating from 400 to $700 \mathrm{~nm}$ (Combes et al., 2000) (Eq. 1):

$\operatorname{PPFD}=\int_{\lambda=400}^{\lambda=700} E h v(\delta \lambda)$, 

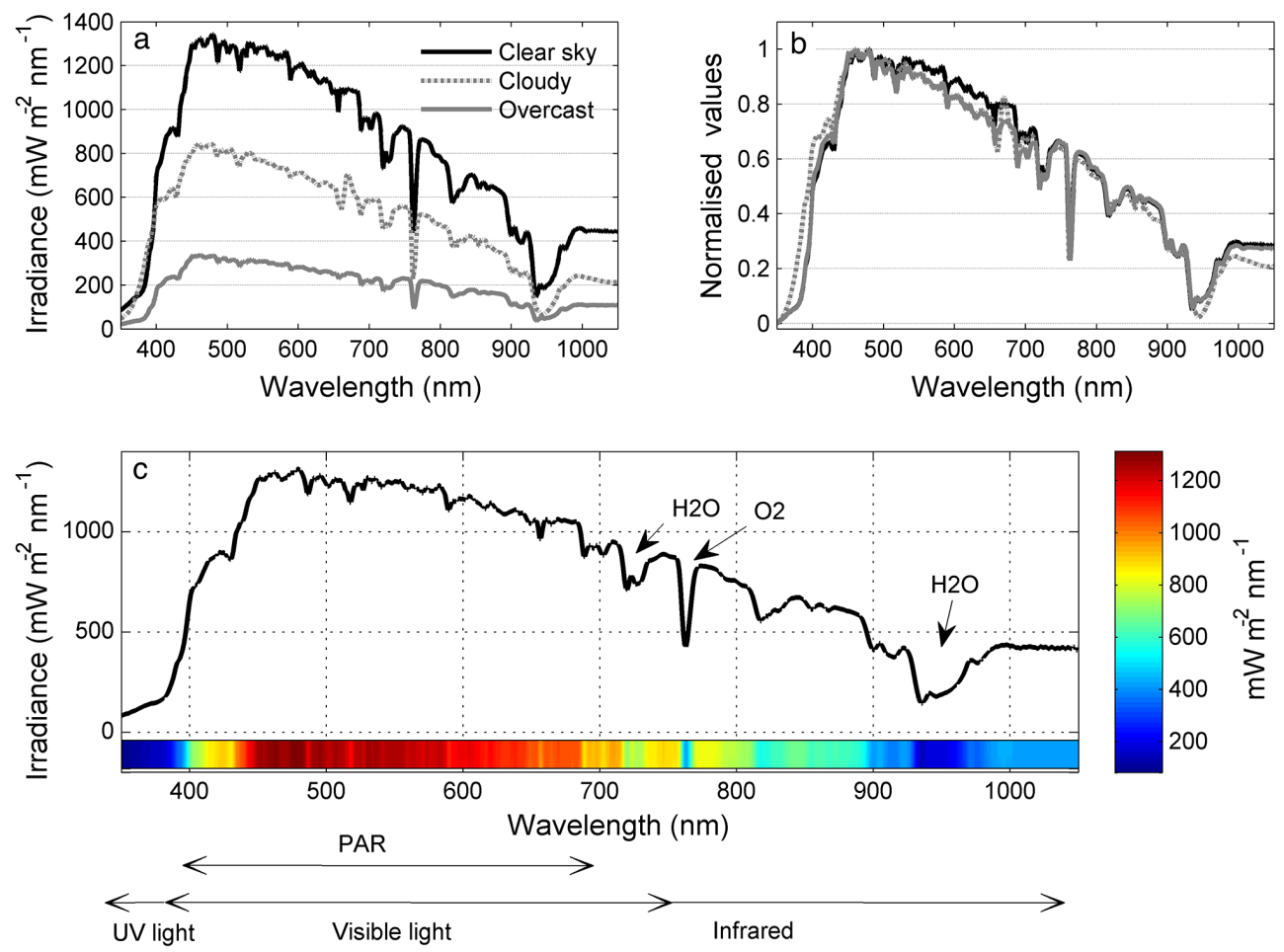

Figure 2. (a) Spectral distribution of solar radiation above the canopy for the three conditions, while (b) is the normalised data of the same data, showing the little variation according to sky condition and time of year. (c) Visualises the spectrum under clear sky, in addition to the colour-coded intensity. This visualisation should help to interpret the spectral distribution in Fig. 3. Furthermore, the main spectral features together with the wavelength distribution for the visible and PAR are shown.

where the limits of wavelength $(\lambda)$ were 400 and $700 \mathrm{~nm} . E$ is the spectral irradiance, $h$ is the Planck constant and $v$ is frequency, given by $1 / \lambda$. The wavelength increments used for the numerical integration were $1 \mathrm{~nm}$. Blue light is often indicated as being $400-500 \mathrm{~nm}$ but we chose $430-470 \mathrm{~nm}$ as it has been shown that those wavelengths evoke stomatal opening (Kuiper, 1964; Mansfield and Meidner, 1966; Zeiger and Field, 1982; Karlsson, 1986).

The transmissivity of PPFD was calculated as the quotient of PPFD at the height $h$ and the simultaneous measured PPFD at $22 \mathrm{~m}$ (top of tower), while the transmissivity of blue light was calculated as the quotient of blue light at the height $h$ and the simultaneously recorded blue part of the irradiance spectrum at $22 \mathrm{~m}$. Hereafter the blue transmissivity of the two diffuse conditions and the blue light transmissivity on the clear day can be visually compared. For an indication of possible photomorphogenetic response, light quality may also be stated as the red : far-red ( $\mathrm{R}: \mathrm{FR})$ ratio of incident radiation and expressed as follows (Hayward, 1984; Holmes and Smith, 1977):

$$
\mathrm{R}: \mathrm{FR}=\frac{\left.\int_{655 \mathrm{~nm}}^{665 \mathrm{~nm}} E_{(} \lambda\right)}{\int_{725 \mathrm{~nm}}^{735 \mathrm{~nm}} E_{(\lambda)}},
$$

where $E$ is the spectral irradiance. Holmes and Smith (1977) note that red : far-red ratio remains more or less constant over the year and during the day, whereas within the canopy it is additionally dependent on the interaction of the incident light with phytoelements.

\subsubsection{Below-canopy PPFD}

High resolution below-canopy photosynthentic photon flux density was measured with a mobile handheld TRAC (Tracing Radiation and the Architecture of Canopies - Leblanc et al. (2002) (3rd Wave Engineering, Nepean, Canada), recording continuously at $32 \mathrm{~Hz}$ along the same transect, resulting in a high resolution data set of total incident (global) and diffuse (through the use of a shading strip) PPFD values. In addition, the TRAC software also estimated LAI, the fraction of absorbed photosynthetically active radiation ( $f$ APAR), gap fraction, gap dimension and the clumping factor. These measurements were carried out immediately after the spectral flux density measurements at solar noon. The TRAC sensor was manually moved along the same transect as used for the spectral irradiance measurements. The standard walking pace along the transect was $0.3 \mathrm{~m} \mathrm{~s}^{-1}$ (while continuously recording), following markers at $5 \mathrm{~m}$ intervals to ensure a consistent high-resolution data set. As data were 

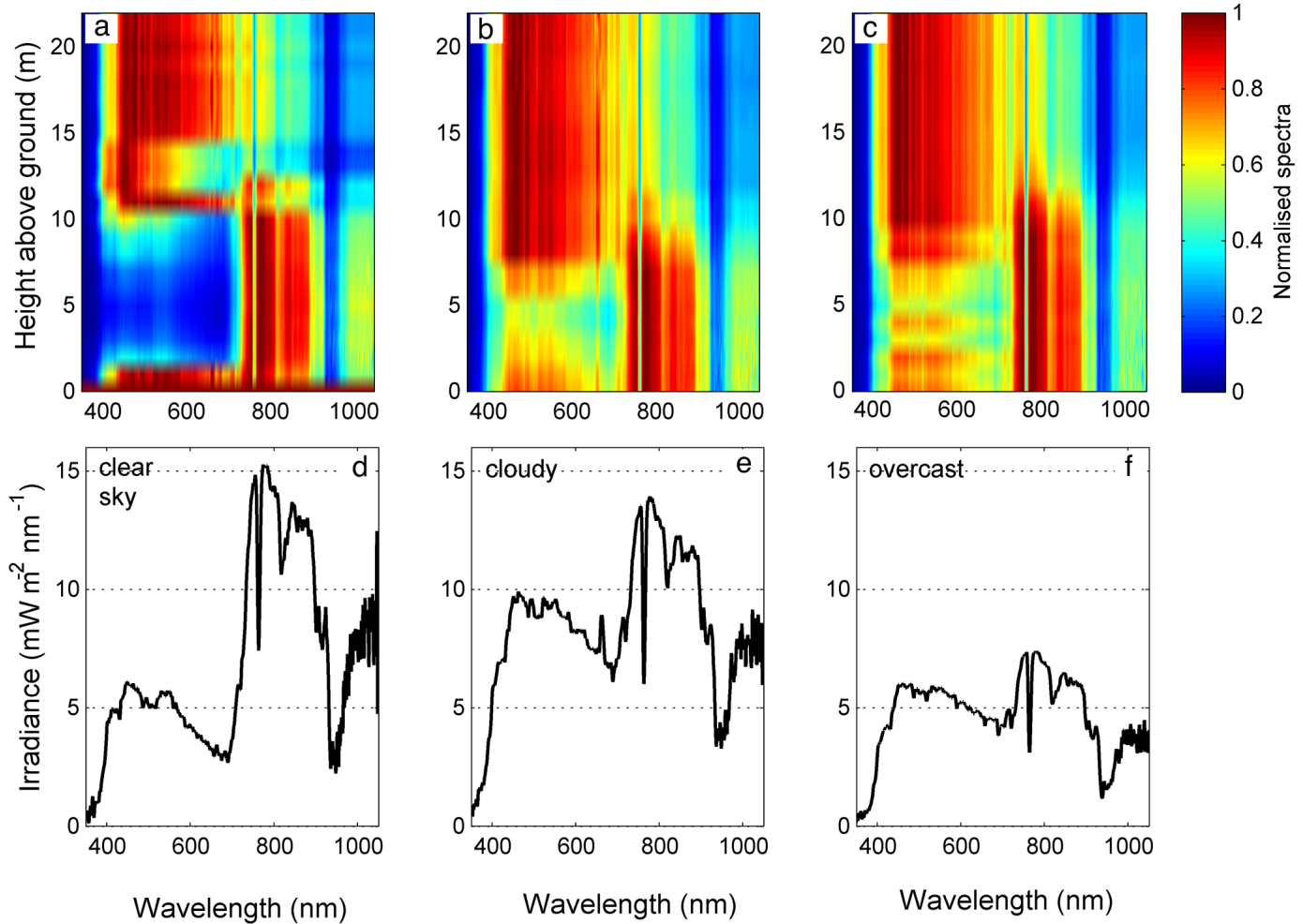

Figure 3. Vertical profile of spectral distribution of solar radiation traversing the forest canopy on a clear, cloudy and overcast day. (a) vertical profile on the clear day; (b) vertical profile on the cloudy day; (c) vertical profile on the overcast day. For the visualisations the data are normalised on a scale from 0 to 1 . (d), (e) and (f) show the spectral distribution at $2 \mathrm{~m}$ above ground in absolute terms, showing the exact energy distribution across all wavelength.

recorded at $32 \mathrm{~Hz}$ not all segments have the identical number of data points. Raw data were logged internally inside the instrument and downloaded after each run before converting and processing them using its own TRAC software. Exact details on theory description, the calculations of gap fraction and dimension, as well as the clumping factor can be found in Chen and Cihlar (1995), Leblanc et al. (2002) and Leblanc (2008).

\subsubsection{Canopy $\mathrm{CO}_{2}$ exchange under such conditions}

As mentioned above, there are only two Sitka spruce forest sites with long-term canopy $\mathrm{CO}_{2}$ exchange measurements: Griffin and Harwood forest (in Northern England). $\mathrm{CO}_{2}$ exchange at canopy scale were carried out in Griffin forest as described in Clement et al. (2007) and Dengel and Grace (2010). Corrections and quality control are applied to data including exclusion of data recorded at low turbulence, reducing the data availability (also for the 3 represented days). Therefore data from the other Sitka spruce forest $(250 \mathrm{~km}$ away, same age, spacing, plantation, etc.) were included in the current study in order to provide a "big picture" on how canopy $\mathrm{CO}_{2}$ exchange of forests are affected by changes in sky conditions and hence light distribution within the forest canopy. Eight consecutive days were included here, as already introduced in Dengel and Grace (2010).

\section{Results}

Figure 1 illustrates the schematics of the forest, along with visual impressions of canopy structure and fish-eye photographs of the canopy and sky taken during the measurements. This forest structure is typical of many commercial coniferous plantations. All above-canopy irradiance spectra display the expected features (Fig. 2c): they have their peak spectral irradiances in the blue region at around $480 \mathrm{~nm}$; both oxygen absorption bands are clearly seen $(687$ and $761 \mathrm{~nm})$, as are the water absorption bands at around 730 and $940 \mathrm{~nm}$.

Below the canopy the absorption pattern is changing, showing high absorption in the PPFD region while little absorption occurs from $700 \mathrm{~nm}$ onwards. Figure $3 \mathrm{a}$ visualises the spectral/energy change that occurs once radiation penetrates the forest canopy on the clear sky day. An abrupt shift is observed at the height where the canopy is closed, with a large sunfleck becoming visible at the heights of around $11 \mathrm{~m}$ above ground in this data set. Hereafter the majority of the energy appears in the infrared region. Once radiation reaches the forest floor which is illuminated partly by sun- 


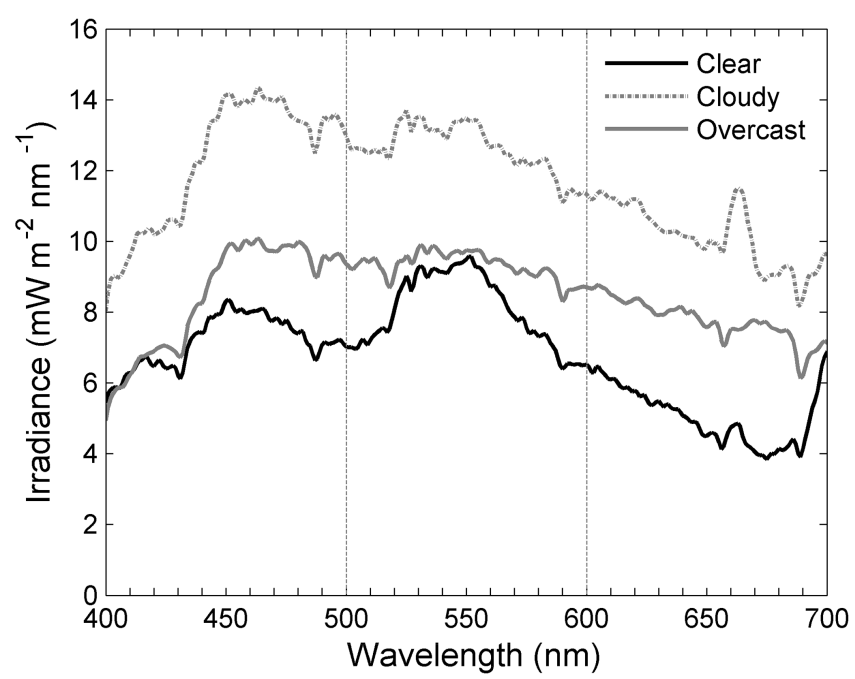

Figure 4. Spectral distribution of solar radiation at $5 \mathrm{~m}$ above the ground for the wavelength range of PAR, showing the various distributions of blue and in particular the fraction of blue wavelength (430-470) that does evoke stomatal opening (sensu Kuiper, 1964; Mansfield and Meidner, 1966).

flecks and by large open parts of the canopy this shift reverses to similar distributions as seen above and close to the top of the canopy. Figure $3 \mathrm{~b}$ and $\mathrm{c}$ represent the spectral flux density recorded in cloudy and overcast conditions, respectively. Here, under both sky conditions, high energy levels within the blue region of the spectra remain conserved much lower/deeper into the canopy, with overcast conditions showing a more even distribution. Within the canopy (around $8 \mathrm{~m}$ above ground) some important differences can be noted between the sky types. Under both cloudy and overcast conditions there is relatively more blue radiation although in absolute irradiances this isn't always true. Much less of the incoming radiation is in the photosynthetically - active part of the spectrum (400-700 nm) in the case of the clear sky compared with the cloudy/overcast conditions. Figure 3d, e and $\mathrm{f}$ show the energy distribution at $2 \mathrm{~m}$ above the forest floor in absolute irradiances showing very similar values for clear and overcast. Higher in the canopy, at $5 \mathrm{~m}$ above the ground (Fig. 4) this pattern is changing with less energy in the blue fraction under the clear sky.

The spectra were re-expressed as quanta and numerically integrated between 400 and $700 \mathrm{~nm}$ to yield values of PPFD (Eq. 2). Above the canopy on top of the $22 \mathrm{~m}$ tall tower PPFD was approximately 1600 on the clear day, 1000 under cloudy conditions and $400 \mu \mathrm{mol} \mathrm{m} \mathrm{m}^{-2} \mathrm{~s}^{-1}$ when overcast, representing three distinctive sky/clearness conditions separated by approx. $600 \mu \mathrm{mol} \mathrm{m}^{-2} \mathrm{~s}^{-1}$ between conditions. The mean and cumulative LAI (Fig. 5a) and PPFD distributions (Fig. 5b) down the vertical profile, and the transmissivity values associated with PPFD (Fig. 5c) and blue light (Fig. 5d) are shown as attenuation curves in Fig. 5, respectively. The attenuation of direct radiation ("clear") is abrupt in the topmost part of the canopy (14-15 m) (Fig. 5b, c). The canopy is inhomogeneous and at around $11 \mathrm{~m}$ above the ground the sensor encountered a large sunfleck, which has produced a very high signal. Under cloudy and overcast conditions the curves are relatively smooth, showing gradual attenuation on passing through the canopy (Fig. 5b, c). These data may also be presented as a classical Beer-Lambert log-plot (Fig. 6), wherein the slope may be used to yield an estimate of the attenuation coefficient $(k)$. The classical Beer-Lambert approach applied to diffuse conditions (Fig. 6 - solid grey and black line) yields $k$ values of 0.79 and 0.81 , respectively. However, under clear sky conditions, this approach is unreliable and cannot be used here, due to the inhomogeneous vertical distribution of foliage, and the presence of a large gap. Overall, the result shows that under sunny conditions a very high fraction of PPFD is absorbed or reflected at the top of the canopy, and therefore much less remains after a leaf area index of 1.5 (in the main canopy).

Figure 5d shows the profile of blue-light irradiance. In clear conditions, it is attenuated substantially, but only slightly attenuated in cloudy or overcast conditions. Close to ground level, blue light increases which we attribute to lateral illumination within the trunk space.

In clear conditions, there was a region of the canopy with a very low red : far-red ratio, usually indicative of deep shade (Fig. 5e-black line). However, there was considerable spatial variation. In large gaps the clear-sky red : far-red ratio is high, reaching near-above canopy values visible in Fig. 5e. Usually, however, the red : far-red ratio is lower, below 0.75 .

The horizontal heterogeneity at the forest floor was surveyed, first by using the spectroradiometer (Fig. 7) and then with the TRAC device (Fig. 8). The spectral flux density, illustrated in Fig. 7, shows the thinning lines clearly. There are distinctive differences within the photosynthetically active part of the spectrum, with higher energy levels in the photosynthetically active part of the spectrum under overcast conditions. Figure $7 \mathrm{a}$ and $\mathrm{b}$ illustrate the spectral flux density along the entire $115 \mathrm{~m}$ long transect $(2.5 \mathrm{~m}$ measurement interval) for the clear and overcast day, respectively (cloudy conditions not shown here). Under both conditions the thinning lines become visible, though the irradiance levels shift (also Fig. 8), depending on light regime. Under clear conditions distinctive sunflecks are visible with high energy (similar to above canopy levels) in the photosynthetically active part of the spectrum. Under overcast conditions high energy levels within the photosynthetically active part of the spectrum are sustained and more evenly distributed along the forest floor. Energy levels within the far-red and infrared regions remain high under both conditions.

In clear-sky conditions the huge variation caused by sunflecks is seen (Fig. 8a), often reaching photon flux values of several hundred $\mu \mathrm{mol} \mathrm{m} \mathrm{m}^{-2} \mathrm{~s}^{-1}$, superimposed on a background that varies systematically with the presence of thinning rows, from a minimum of about 3 to a maximum 

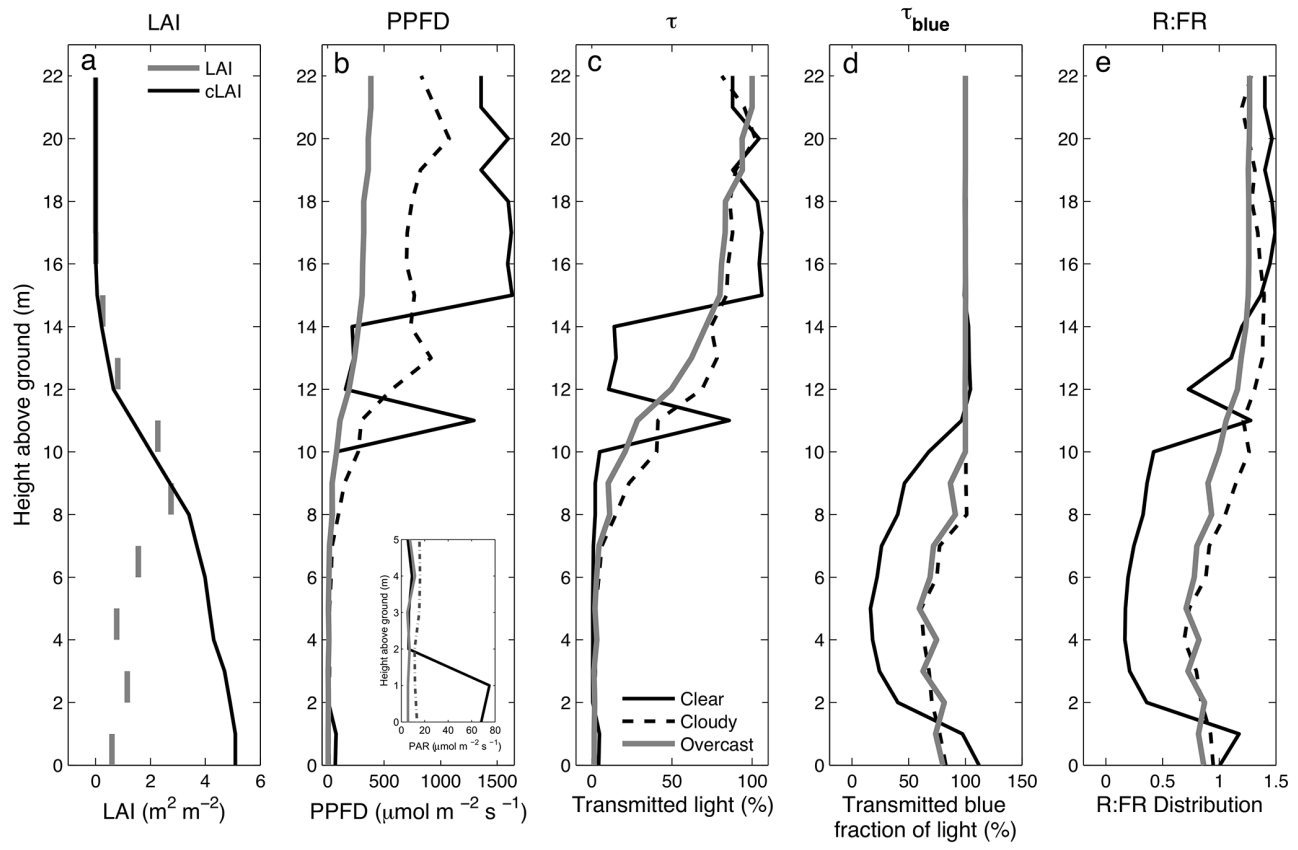

Figure 5. (a) vertical distribution of leaf area index (LAI) and cumulative leaf area index (cLAI); (b) vertical distribution of photosynthetic flux density (PPFD) on a clear day (black line), cloudy day (pecked black line), overcast day (grey line). The insert is a magnification of the lowest $5 \mathrm{~m}$ above the forest floor, showing the forest floor illumination caused by sunflecks; (c) the same as (b) but normalised as transmissivity; (d) transmissivity of blue light; (e) vertical profile of the red : far-red ratio (R: FR).

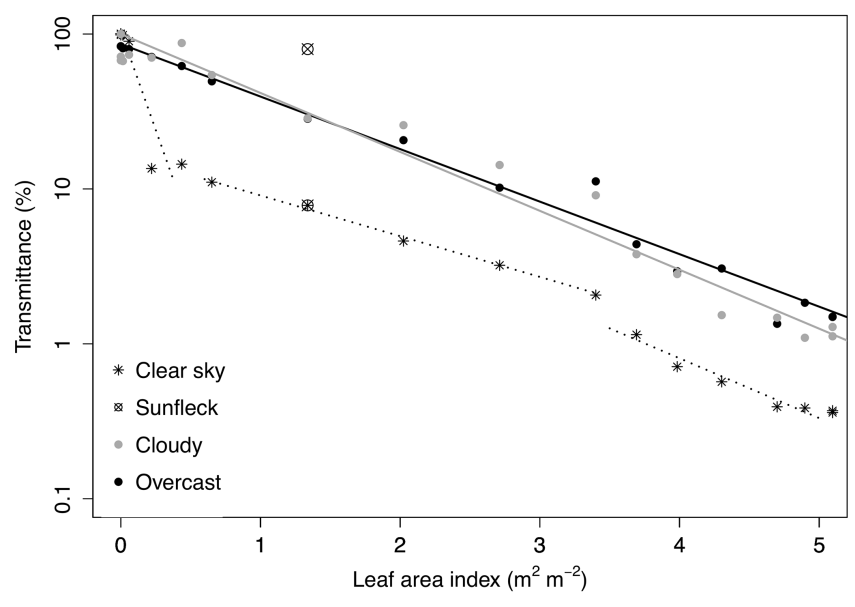

Figure 6. Transmissivity and attenuation curves according to the Monsi and Saeki (1953) method. Transmissivity and light attenuation through the forest canopy after applying the Beer-Lambert attenuation law. Stars and dotted lines represent clear sky, grey solid circles and the grey line represent cloudy and solid black circles and the black line represent the overcast conditions.

of about $20 \mu \mathrm{mol} \mathrm{m}{ }^{-2} \mathrm{~s}^{-1}$. Overcast conditions (Fig. 8b) show highly regular behaviour, closely resembling the "background' values shown in Fig. 8a, although much higher.

As a "big picture" overview on how canopy $\mathrm{CO}_{2}$ exchange and the light use efficiency (LUE) in Sitka spruce is behav- ing under such conditions we included data from 8 consecutive days from Harwood forest. Canopy $\mathrm{CO}_{2}$ fluxes from Harwood forest show generally the same flux variability and range throughout the year as in Griffin forest (data not shown here). These 8 days show the day-to-day changes in light use efficiency when sky conditions change from overcast to cloudy to clear sky conditions. After 4 consecutive clear days (lowest light use efficiency) these are followed again by a cloudy and an overcast day and are evident in Fig. 9.

\section{Discussion}

The study introduced here, carried out in Griffin forest, is the first to report on both the vertical and an extensive horizontal transect through a forest plantation.

\subsection{Spectral effects}

The spectral distribution of radiation is very important for plant growth and morphogenesis (Endler, 1993; EscobarGutuérrez et al., 2009). The spectral distribution of incoming solar radiation was similar under all three sky conditions. However, substantially more energy in the photosynthetically active wavebands penetrated the canopy in the case of diffuse skies. There was significantly more blue light within the canopy under cloudy skies, possibly a result of multiple reflections and scattering involving the waxy abaxial surfaces of needles (Jeffree et al., 1971; Reicosky and Hanover, 

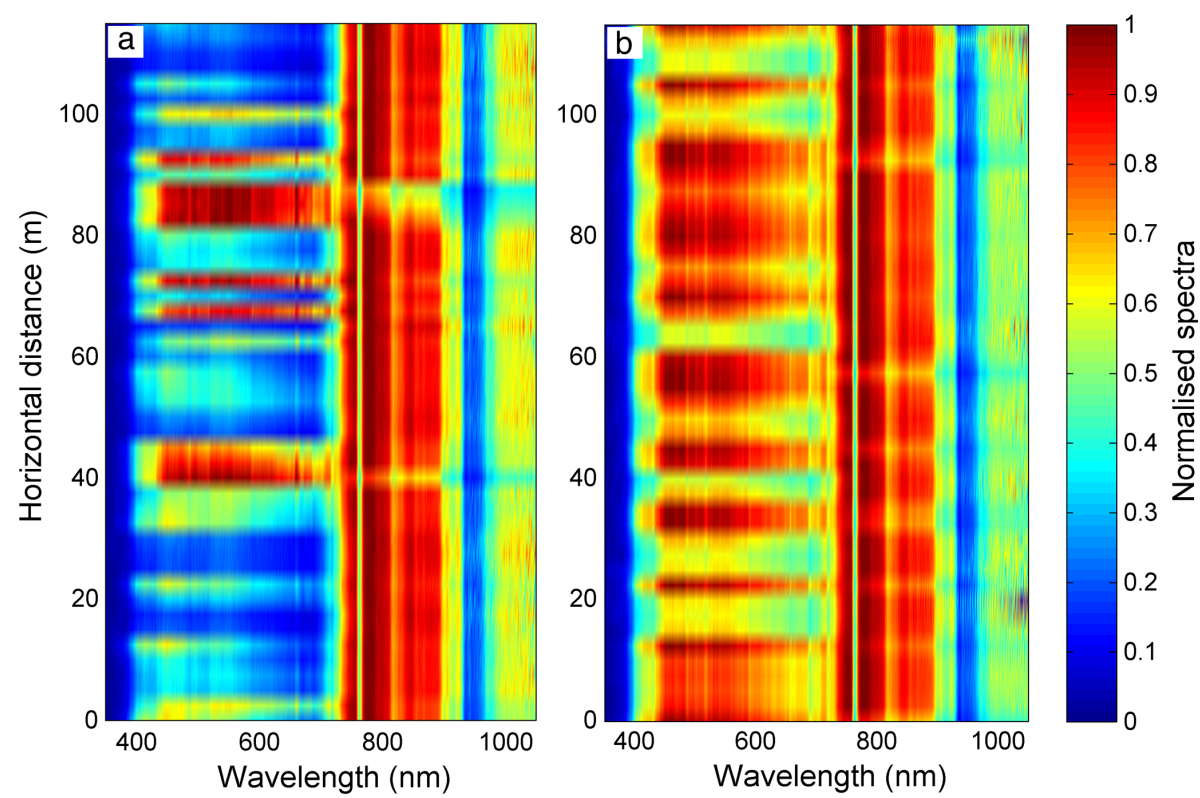

Figure 7. Normalised spectra along the $115 \mathrm{~m}$ transect on the clear (a) and on the overcast day (b) respectively, showing clearly the distribution of sunflecks and open spaces (on the clear day) and the thinning lines on the overcast day (b).

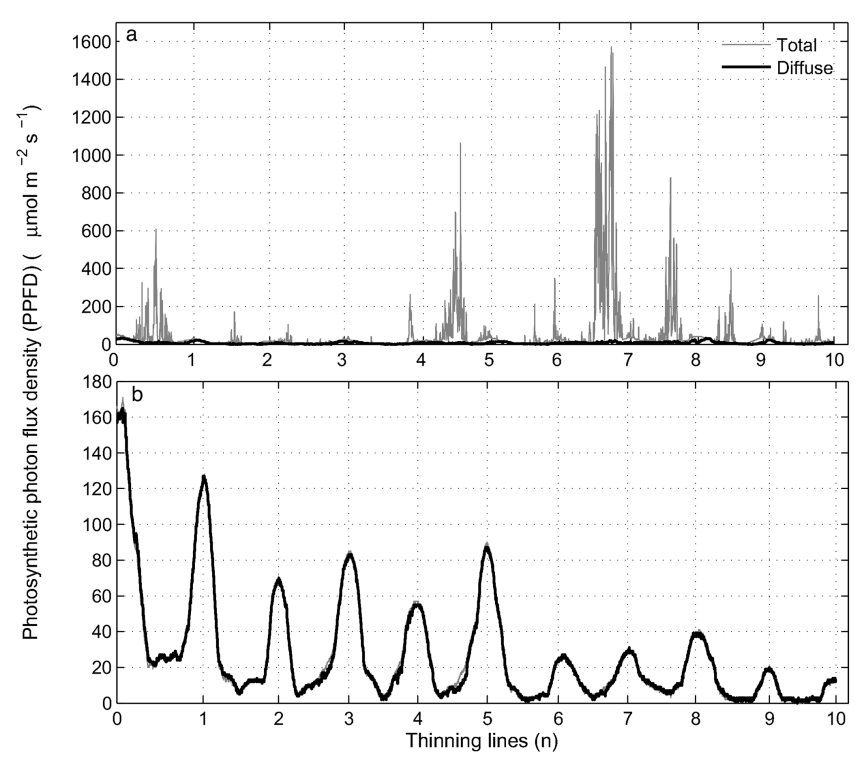

Figure 8. Photosynthetic photon flux density (PPFD) distribution below the forest canopy under clear sky (a) and under overcast (b) conditions. Total (global) PPFD is marked as a solid grey line, while diffuse PPFD measured simultaneously (using a shading strip) is marked as a solid black line. Thinning lines are every $11 \mathrm{~m}$.

1978; Cape and Percy, 1993). Differences in the directional properties of direct vs. diffuse radiation may also have a role in explaining this difference. Blue-enrichment may have important implications for stomatal control of photosynthesis and water use. For Scots pine and Sitka spruce, Morison and Jarvis (1983) reported that blue wavelengths are more effective in causing stomatal opening than red wavelengths. Smith (1982) reported that at low PPFD stomata open only in response to blue light, red light being ineffective; thus, if Smith's is a general result, we may conclude that the conditions of diffuse radiation in the present case are especially conducive to stomatal opening in the lower regions of the canopy, where PPFD is low in all three conditions.

Within the canopy there is a very high proportion of nearinfrared under all three sky conditions. This is not surprising, as leaves generally transmit as much as $50 \%$ of incident radiation at this waveband and reflect much of the remaining (Middleton and Walter-Shea, 1995; Middleton et al., 1997; Knapp and Carter, 1998; Combes et al., 2000; Carter and Knapp, 2001). On the other hand, in the chlorophyllabsorbing region of the red, leaves transmit rather little energy; therefore, the ratio of red to far red is dictated by the presence of leaves. This aspect of light quality has received much attention. The decline in the red : far-red ratio has long been known and has been linked in numerous studies to aspects of photomorphogenesis (see reviews by Federer and Tanner, 1966; Smith, 1982; Woodward, 1983; Morgan et al., 1985; Endler, 1993). In the present study, we have found that the red: far-red ratio in the canopy is much lower under clear skies (Hertel et al., 2011), indicating a lower photomorphogenical "light quality" (sensu Smith, 1982) than under diffuse conditions. 


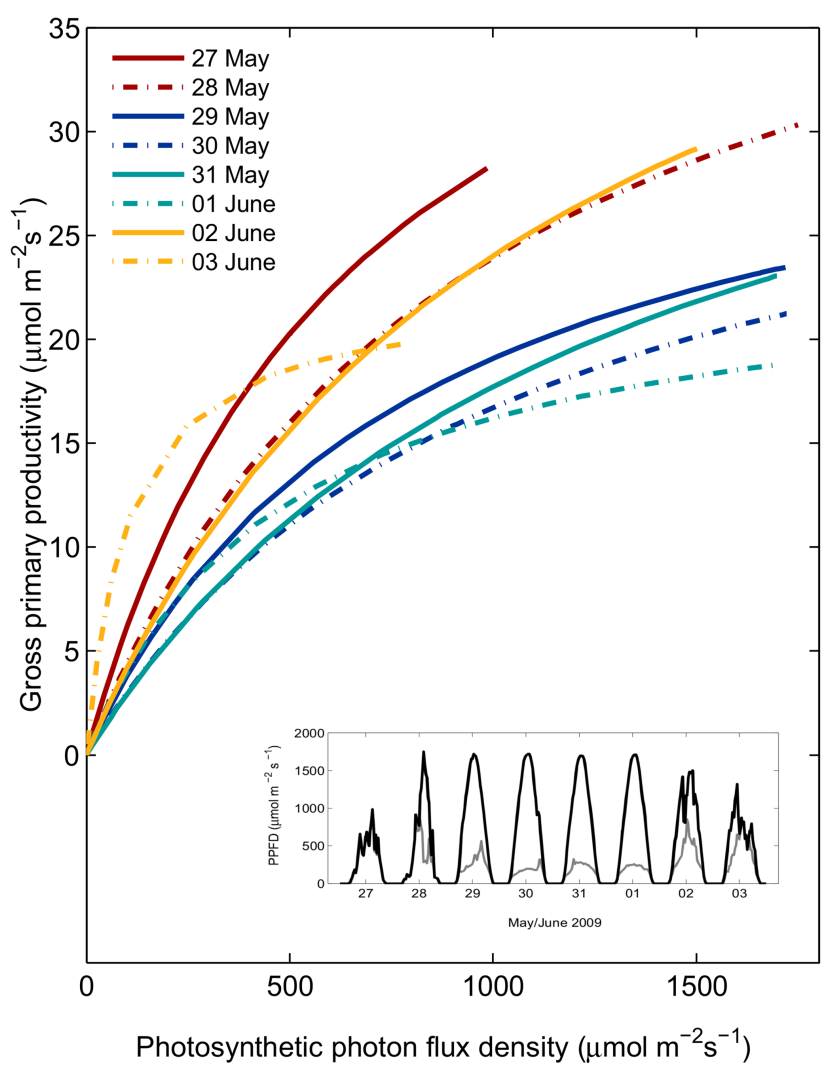

Figure 9. Light use efficiency (LUE) curves for 8 consecutive days previously introduced in Dengel and Grace (2010). These show the day-to-day changes in light use efficiency when sky conditions change from overcast to cloudy to clear sky conditions. After 4 consecutive clear days (lowest light use efficiency) these are followed again by a cloudy and an overcast day. The scales represent the gross primary productivity (GPP) estimated for these days together with the corresponding photosynthetic photon flux density (PPFD). The insert is a modified reproduction from Dengel and Grace (2010, Fig. 2c), representing global radiation in black and diffuse radiation in grey.

\subsection{Contrasting light attenuation under cloudy vs. clear skies}

It is evident that there are profound differences in the transmissivity of solar radiation under the different sky conditions. The most important of these differences is the extent to which the direct sunlight is absorbed or reflected near the top of the canopy, shown by the attenuation patterns. This energy is therefore not available for photosynthesis lower down in the canopy. It is also shown, quite independently, by the extent to which the diffuse irradiation is relatively higher at the forest floor and by the distribution of ground-level data between transmission classes (data not shown here). The same phenomenon was shown by Morgan et al. (1985) for pine canopies and by Leuchner et al. (2005), Navratil et al. (2007) and Urban et al. $(2007,2012)$ for Norway spruce.
The vertical profile under sunny conditions demonstrated only a poor fit to the Beer-Lambert law because of the canopy's inhomogeneity. Further data integrating spatially and temporally would of course reduce the uncertainty in our estimated $k$ value. There was marked variation in the attenuation coefficient $k$, also in the data shown by Norman and Jarvis (1974) and Lewandowska et al. (1977), who obtained similar $k$ values to those reported here for the same species. Smith (1993) also stated that a single extinction coefficient using the Beer's law model cannot be used effectively to predict the light penetration in Douglas fir (Pseudotsuga menziesii). We presume that part of the explanation of this variation lies in the variable structure as one proceeds from the top to the bottom of the canopy: near the top the leaves are densely crowded on the stems, whereas near the bottom leaves are thin, sparse and attenuation is dominated by branches and stems (Norman and Jarvis, 1974; Schulze et al., 1977; Ford, 1982; Leverenz et al., 1982; Stenberg et al., 1998).

One obvious difference between clear sky radiation and overcast skies is the directional distribution of the radiation. From a general consideration of the angular distribution of brightness of an overcast sky (Grace, 1971), it is apparent that proportionately more energy from low-angle rays of skylight will penetrate the canopy. Such low-angle light may be important in the photosynthesis of vertically aligned leaves but this effect will be underestimated by a cosine-corrected horizontal sensor. For this reason, spherical sensors have sometimes been advocated for in-canopy use (Biggs, 1986), as they more closely resemble the near-spherical distribution of leaf angles in a forest canopy.

\subsection{Gaps and sunflecks determine spatial patterns}

There are two types of gaps that can occur in forest stands, firstly, natural gaps as the result of the clumping of leaves and stems i.e. the structure and orientation of the coniferous shoot and the needles they hold (Norman and Jarvis, 1974; Leverenz et al., 1982). The second type of gap is artificial, created through forest management (planting design and thinning regime).

Under clear skies the occurrences of gaps in the crown, which are sometimes short-lived (seconds to minutes) and wind-dependent (Federer and Tanner, 1966; Pearcy, 1990; Chazdon and Pearcy, 1991), are spots where the direct radiation beam, or some fraction of it, penetrates into the canopy (Fig. 1, lower schematics), sometimes as far as the forest floor (Stenberg, 1995). They create highly illuminated areas where the incident light can in extremis reach higher values than above the canopy itself due to lateral illumination in the trunk space and a high proportion of scattering of radiation on the surrounding branches (Muller, 1971). Sunfleck spectra are similar to incident radiation (Endler, 1993; Combes et al., 2000; Leuchner et al., 2012) and may also be areas with transient higher temperatures, which in some cases may 
have physiological significance. Sunflecks also have red : farred ratios (Fig. 3e) close to those measured above the canopy (Reitmayer et al., 2001; Leuchner et al., 2012).

At the forest floor a complex spatial pattern of sunflecks is generally seen. The intensity of the sunflecks shows that almost always they contain substantial penumbral components (Stenberg, 1995). They appear not in the thinning lines but below the trees themselves: under clear sky conditions there is a lateral shift in the total penetrated radiation compared with the diffuse skies. This phenomenon is visible because the tree planting lines in this forest happen to be oriented east-west, and at the prevailing solar angles the beam must pass through a large thickness of canopy in order to reach the ground. However, under overcast conditions solar radiation distribution follows the thinning pattern with highest radiation values recorded inside the thinning lines.

As these measurements were carried out around solar noon in summer, the path through the canopy was minimal and radiation values below the canopy are likely to be near their maximum. This high insolation distribution does not remain constant during the day due to the planting orientation and thinning pattern. These radiation distributions do of course change over the course of a clear day with highest values within the thinning lines early and later in the day, respectively (Reifsnyder, 1989; Leuchner et al., 2012). An aspect not investigated within the frame of the current study is the below canopy vegetation, which is also influenced by the type of forest management. At this site, the below canopy vegetation is much more pronounced in the thinning lines than below the canopy itself, as it is visible in the sidewise taken hemispherical image in Fig. 1.

\subsection{Implications for $\mathrm{CO}_{2}$ exchange under such conditions}

As shown in many studies (Gu et al., 1999, 2002; Urban et al., 2007, 2012; Dengel and Grace, 2010) diffuse radiation enhances photosynthesis in terrestrial vegetation. Urban et al. $(2007,2012)$ and Dengel and Grace (2010) hypothesised that optimal photosynthetic activity of the canopy is achieved under diffuse radiation (cloudy and overcast) conditions, when scattered light penetrates throughout the canopy, illuminating all the leaves to some extent and providing a more uniform distribution of light between the leaves.

Leverenz and Jarvis $(1979,1980)$ determined light response curves of this Picea species under controlled conditions and found light saturation at around $500 \mu \mathrm{mol} \mathrm{m}^{-2} \mathrm{~s}^{-1}$, a value which is often exceeded at the top of the canopy. Similar over-saturation values are visible in the current study. If the uppermost level of a canopy is experiencing an oversaturation of light and also encountering the highest shoot temperatures in the forest, it is possible that stress responses such as closure of stomata may occur (in this species stomata tend to close at high leaf-to-air vapour pressure difference, Grace et al., 1975; Neilson and Jarvis, 1975; Alton et al., 2007). Other stress responses such as photoinhibition are also possible (Powles, 1984; Krause, 1988; Long et al., 1994). Thus, along the sunfleck pathway, such effects may contribute to under-activity of photosynthesis in relation to the level of incident radiation (Pearcy, 1990; Kanniah et al., 2012).

Given the poor penetration of direct radiation into the canopy, and the possible stress effects of PPFD values in excess of $500 \mu \mathrm{mol} \mathrm{m}{ }^{-2} \mathrm{~s}^{-1}$, we can now ask: what influence do sky conditions have on the photosynthesis of the canopy? In an earlier study on a very similar canopy we showed that light was used more efficiently under diffuse irradiance (see Fig. 9, insert is modified from Dengel and Grace 2010). In that study we found the quantum efficiency under direct radiation to be 28.6 , but $41.0 / 50.1$ under cloudy and overcast conditions, respectively. Moreover, tree ring analysis showed that diffuse radiation does not only influence gas exchange in the short-term (hourly, daily, monthly), but also influences long-term forest growth (Dengel et al., 2009).

Author contributions. S. Dengel has designed and carried out the experiment, processed the data and written the manuscript. J. Grace has contributed to the design of the experiment, the data interpretation and actively contributed to the manuscript writing. A. MacArthur has taken part in the training and experiment itself and has contributed to the data processing and manuscript writing.

Acknowledgements. This study was part of a $\mathrm{PhD}$ study funded by the Torrance Bequest and a School of GeoSciences scholarship, University of Edinburgh. The study introduced in the current work is part of a mini project approval by NERC (National Environmental Research Council, UK) and is assisted by the loan of the paired spectrometers by NERC FSF (Edinburgh). The authors would like to thank Terry Dawson for providing the TRAC system and the staff at the NERC Field Spectroscopy Facility (FSF) (Edinburgh) for their support. Furthermore the authors would like to thank Anitra Fraser for her support in the field.

Edited by: G. Wohlfahrt

\section{References}

Alton, P. B., North, P. N., and Los, S. O.: The impact of diffuse sunlight on canopy light-use efficiency, gross photosynthetic product and net ecosystem exchange in three forest biomes, Glob. Change Biol., 13, 776-787, 2007.

Biggs, W.: Radiation Measurement, Adv. Agricul. Measurem., 111, 3-20, 1986.

Cape, J. N. and Percy, K. E.: Environmental influences on the development of spruce needle cuticles, New Phytol., 125, 787-799, 1993.

Carter, G. A. and Knapp, A. K.: Leaf optical properties in higher plants: linking spectral characteristics to stress and chlorophyll concentration, Am. J. Botany, 88, 677-684, 2001. 
Casal, J. J.: Photoreceptor signaling networks in plant responses to shade, Ann. Rev. Plant Biol., 64, 403-427, 2013.

Chazdon, R. L. and Pearcy, R. W.: The Importance of Sunflecks for Forest Understory Plants, BioScience, 41, 760-766, 1991.

Chen, J. M. and Cihlar, J.: Quantifying the effect of canopy architecture on optical measurements of leaf area index using two gap size analysis methods, Geosci. Remote Sens., 33, 777-787, 1995.

Chen, J. M., Blanken, P. D., Black, T. A., Guilbeault, M., and Chen, S.: Radiation regime and canopy architecture in a boreal aspen forest, Agr. Forest Meteorol., 86, 107-125, 1997a.

Chen, J. M., Rich, P. M., Gower, S. T., Norman, J. M., and Plummer, S.: Leaf area index of boreal forests: Theory, techniques, and measurements, J. Geophys. Res.-Atmos., 102, 29429-29443, 1997b.

Clement, R.: Mass and energy exchange of a plantation forest in Scotland using micrometeorological methods, $\mathrm{PhD}$ Thesis, School of Geosciences, University of Edinburgh, 2004.

Clement, R., Moncrieff, J. B., and Jarvis, P. G.: Net carbon productivity of Sitka Spruce forest in Scotland, Scottish Forest., 57, 5-10, 2003.

Combes, D., Sinoquet, H., and Varlet-Grancher, C.: Preliminary measurement and simulation of the spatial distribution of the Morphogenetically Active Radiation (MAR) within an isolated tree canopy, Ann. Forest Sci., 57, 497-511, 2000.

Dengel, S. and Grace, J.: Carbon dioxide exchange and canopy conductance of two coniferous forests under various sky conditions, Oecologia, 164, 797-808, 2010.

Dengel, S., Aeby, D., and Grace, J.: A relationship between galactic cosmic radiation and tree rings, New Phytol., 184, 545-551, 2009.

Endler, J. A.: The Color of Light in Forests and Its Implications, Ecol. Monogr., 63, 1-27, 1993.

Escobar-Gutiérrez, A. J., Combes, D., Rakocevic, M., de Berranger, C., Eprinchard-Ciesla, A., Sinoquet, H., and Varlet-Grancher, C.: Functional relationships to estimate Morphogenetically Active Radiation (MAR) from PAR and solar broadband irradiance measurements: The case of a sorghum crop, Agr. Forest Meteorol., 149, 1244-1253, 2009.

Federer, C. A. and Tanner, C. B.: Spectral Distribution of Light in Forest, Ecology, 47, 555-560, 1966.

Ford, E. D.: High Productivity in a Polestage Sitka Spruce Stand and its Relation to Canopy Structure, Forestry, 55, 1-17, 1982.

Frazer, G. W., Canham, C. D., and Lertzman, K. P.: Gap Light Analyzer (GLA), Version 2.0: Imaging software to extract canopy structure and gap light transmission indices from truecolor fisheye photographs, Copyright 1999, Simon Fraser University, Burnaby, BC, and the Institute of Ecosystem Studies, Millbrook, New York, 1999.

Gates, D. M.: Energy, plants, and ecology, Ecology, 1-13, 1965.

Gholz, H. L., Vogel, S. A., Cropper, W. P., Jr., McKelvey, K., Ewel, K. C., Teskey, R. O., and Curran, P. J.: Dynamics of Canopy Structure and Light Interception in Pinus Elliottii Stands, North Florida, Ecol. Monogr., 61, 33-51, 1991.

Grace, J.: The Directional Distribution of Light in Natural and Controlled Environment Conditions, J. Appl. Ecol., 8, 155-160, 1971.

Grace, J. and Woolhouse, H. W.: A Physiological and Mathematical Study of the Growth and Productivity of a Calluna-sphagnum
Community, II. Light Interception and Photosynthesis in Calluna, J. Appl. Ecol., 10, 63-76, 1973.

Grace, J., Malcolm, D. C., and Bradbury, I. K.: The Effect of Wind and Humidity on Leaf Diffusive Resistance in Sitka Spruce Seedlings, J. Appl. Ecol., 12, 931-940, 1975.

Grant, R.: Partitioning of biologically active radiation in plant canopies, Internat. J. Biometeorol., 40, 26-40, 1997.

Gu, L., Fuentes, J. D., Shugart, H. H., Staebler, R. M., and Black, T. A.: Responses of net ecosystem exchanges of carbon dioxide to changes in cloudiness: Results from two North American deciduous forests, J. Geophys. Rese., 104, 31421-31434, 1999.

Gu, L., Baldocchi, D., Verma, S. B., Black, T. A., Vesala, T., Falge, E. M., and Dowty, P. R.: Advantages of diffuse radiation for terrestrial ecosystem productivity, J. Geophys. Res., 107, 2-23, 2002.

Hale, S. E.: The effect of thinning intensity on the below-canopy light environment in a Sitka spruce plantation, Forest Ecol. Manage., 179, 341-349, 2003.

Hayward, P. M.: Determination of phytochrome parameters from radiation measurements, in: Techniques in Photomorphogenesis, edited by: Smith, H. and Holmes, M. G., Academic Press London, 159-173, 1984.

Hertel, C., Leuchner, M., and Menzel, A.: Vertical variability of spectral ratios in a mature mixed forest stand, Agr. Forest Meteorol., 151, 1096-1105, 2011.

Holmes, M. G. and Smith, H.: The Function of Phytochrome in the Natural Environment, IV. Light Quality and Plant Development, Photochem. Photobiol., 25, 551-557, 1977.

Jeffree, C. E., Johnson, R. P. C., and Jarvis, P. G.: Epicuticular wax in the stomatal antechamber of sitka spruce and its effects on the diffusion of water vapour and carbon dioxide, Planta, 98, 1-10, 1971.

Kanniah, K. D., Beringer, J., North, P., and Hutley, L.: Control of atmospheric particles on diffuse radiation and terrestrial plant productivity A review, Prog. Phys. Geogr., 36, 209-237, 2012.

Karlsson, P. E.: Blue light regulation of stomata in wheat seedlings. II. Action spectrum and search for action dichroism, Physiol. Plantarum, 66, 207-210, 1986.

Kasperbauer, M. J.: Spectral Distribution of Light in a Tobacco Canopy and Effects of End-of-Day Light Quality on Growth and Development, Plant Physiol., 47, 775-778, 1971.

Kasperbauer, M. J.: Far-Red Light Reflection from Green Leaves and Effects on Phytochrome-Mediated Assimilate Partitioning under Field Conditions, Plant Physiol., 85, 350-354, 1987.

Knapp, A. K. and Carter, G. A.: Variability in leaf optical properties among 26 species from a broad range of habitats, Am. J. Botany, 85, 940-946, 1998.

Krause, G. H.: Photoinhibition of photosynthesis, An evaluation of damaging and protective mechanisms, Physiol. Plantarum, 74, 566-574, 1988.

Kuiper, P. J. C.: Dependence upon Wavelength of Stomatal Movement in Epidermal Tissue of Senecio odoris, Plant Physiol., 39, 952-955, 1964.

Leakey, A. D. B., Press, M. C., and Scholes, J. D.: High-temperature inhibition of photosynthesis is greater under sunflecks than uniform irradiance in a tropical rain forest tree seedling, Plant Cell Environ., 26, 1681-1690, 2003.

Leblanc, S. G.: DHP-TRACWin Manual. Natural Resources Canada, Canada Centre for Remote Sensing, Version 1.0.1, 2008. 
Leblanc, S. G., Chen, J. M., and Kwong, M.: Tracing Radiation and Architecture of Canopies, TRAC Manual Version 2.1 27, Natural Resources Canada, Canada Centre for Remote Sensing, 2002.

Leuchner, M., Fabian, P., and Werner, H.: Spectral Multichannel Monitoring of Radiation within a Mature Mixed Forest, Plant Biol., 7, 619-627, 2005.

Leuchner, M., Menzel, A., and Werner, H.: Quantifying the relationship between light quality and light availability at different phenological stages within a mature mixed forest, Agricul. Forest Meteorol., 142, 35-44, 2007.

Leuchner, M., Hertel, C., Rötzer, T., Seifert, T., Weigt, R., Werner, H., and Menzel, A.: Solar radiation as a driver for growth and competition in forest stands, in: Growth and Defence in Plants, Springer Berlin Heidelberg, 175-191, 2012.

Leverenz, J., Deans, J. D., Ford, E. D., Jarvis, P. G., Milne, R., and Whitehead, D.: Systematic Spatial Variation of Stomatal Conductance in a Sitka Spruce Plantation, J. Appl. Ecol., 19, 835851,1982

Leverenz, J. W. and Jarvis, P. G.: Photosynthesis in Sitka Spruce. VIII. The Effects of Light Flux Density and Direction on the Rate of Net Photosynthesis and the Stomatal Conductance of Needles, J. Appl. Ecol., 16, 919-932, 1979.

Leverenz, J. W. and Jarvis, P. G.: Photosynthesis in Sitka Spruce (Picea Sitchensis (Bong.) Carr.), X. Acclimation to Quantum Flux Density Within and Between Trees, J. Appl. Ecol., 17, 697708, 1980

Lewandowska, M., Hart, J. W., and Jarvis, P. G.: Photosynthetic Electron Transport in Shoots of Sitka Spruce from Different Levels in a Forest Canopy, Physiol. Plantarum, 41, 124-128, 1977.

Long, S. P., Humphries, S., and Falkowski, P .G.: Photoinhibition of Photosynthesis in Nature, Ann. Rev. Plant Physiol. Plant Molecul. Biol., 45, 633-662, 1994.

MacArthur, A., MacLellan, C. J., and Malthus, T.: The fields of view and directional response functions of two field spectroradiometers, Geosci. Remote Sens., 50, 3892-3907, 2012.

Mansfield, T. A. and Meidner, H.: Stomatal Opening in Light of Different Wavelengths: Effects of Blue Light Independent of Carbon Dioxide Concentration, J. Experiment. Botany, 17, 510-521, 1966.

Middleton, E. M. and Walter-Shea, E. A.: Optical properties of canopy elements in the boreal forest, in: Geoscience and Remote Sensing Symposium, 1995, Quant. Remote Sens. Sci. Appl., 1, 789-793, 1995.

Middleton, E. M., Chan, S. S., Rusin, R. J., and Mitchell, S. K.: Optical properties of black spruce and jack pine needles at BOREAS sites in Saskatchewan, Canada, Canad. J.Remote Sens., 23, 108119, 1997.

Monsi, M. and Saeki, T.: On the Factor Light in Plant Communities and its Importance for Matter Production, Ann. Botany, 95, 549567, 2005

Morgan, D. C., Warrington, I. J., and Rook, D. A.: Some observations on the spectral distribution characteristics of short-wave radiation within Pinus radiata D. Don canopies, Plant Cell Environ., 8, 201-206, 1985

Morison, J. I. L. and Jarvis, P. G.: Direct and Indirect Effects of Light on Stomata .1. in Scots Pine and Sitka Spruce, Plant Cell Environ., 6, 95-101, 1983.

Muller, R. A.: Transmission components of solar radiation in pine stands in relation to climatic and stand variables, Pacific South- west Forest and Range Experiment Station, Forest Service, US Department of Agriculture, 13 pp., 1971.

Navrátil, M., Špunda, V., Marková, I., and Janouš, D.: Spectral composition of photosynthetically active radiation penetrating into a Norway spruce canopy: the opposite dynamics of the blue/red spectral ratio during clear and overcast days, Trees Struct. Funct., 21, 311-320, 2007.

Neilson, R. E. and Jarvis, P. G.: Photosynthesis in Sitka Spruce (Picea-Sitchensis (Bong) Carr.), VI. Response of Stomata to Temperature, J. Appl. Ecol., 12, 879-891, 1975.

Norman, J. M. and Jarvis, P. G.: Photosynthesis in Sitka Spruce (Picea sitchensis (Bong.) Carr.), III. Measurements of Canopy Structure and Interception of Radiation, J. Appl. Ecol., 11, 375398, 1974.

Pearcy, R. W.: Sunflecks and Photosynthesis in Plant Canopies, Ann. Rev. Plant Phys., 41, 421-453, 1990.

Powles, S. B.: Photoinhibition of Photosynthesis Induced by Visible Light, Ann. Rev. Plant Physiol., 35, 15-44, 1984.

Reicosky, D. A. and Hanover, J. W.: Physiological Effects of Surface Waxes: I. Light Reflectance for Glaucous and Nonglaucous Picea pungens, Plant Physiol., 62, 101-104, 1978.

Reifsnyder, W. E.: Control of solar radiation in agroforestry practice, In Reifsnyder WE, Darnhofer TO, eds., Meteorology and Agroforestry, ICRAF, Nairobi, Kenya, 141-156, 1989.

Reitmayer, H., Werner, H., and Fabian, P.: A Novel System for Spectral Analysis of Solar Radiation within a Mixed BeechSpruce Stand, Plant Biol., 4, 228-233, 2002.

Ritchie, G. A.: Evidence for red:far red signaling and photomorphogenic growth response in Douglas-fir (Pseudotsuga menziesii) seedlings, Tree Physiol., 17, 161-168, 1997.

Schulze, E. D., Fuchs, M. I., and Fuchs, M.: Spacial distribution of photosynthetic capacity and performance in a mountain spruce forest of Northern Germany, Oecologia, 29, 43-61, 1977.

Sellers, P. J.: Canopy reflectance, photosynthesis and transpiration, Internat. J. Remote Sens., 6, 1335-1372, 1985.

Smith, F. W., Sampson, D. A., and Long, J. N.: Comparison of LeafArea Index Estimates from Tree Allometrics and Measured Light Interception, Forest Sci., 37, 1682-1688, 1991.

Smith, H.: Light Quality, Photoperception, and Plant Strategy, Ann. Rev. Plant Physiol., 33, 481-518, 1982.

Smith, N. J.: Estimating leaf area index and light extinction coefficients in stands of Douglas-fir (Pseudotsuga menziesii), Can. J. Forest Res., 23, 317-321, 1993.

Sonohat, G., Balandier, P., and Ruchaud, F.: Predicting solar radiation transmittance in the understory of even-aged coniferous stands in temperate forests, Ann. Forest Sci., 61, 629-641, 2004.

Stenberg, P.: Penumbra in within-shoot and between-shoot shading in conifers and its significance for photosynthesis, Ecol. Modell., 77, 215-231, 1995.

Stenberg, P., Smolander, H., Sprugel, D., and Smolander, S.: Shoot structure, light interception, and distribution of nitrogen in an Abies amabilis canopy, Tree Physiol., 18, 759-767, 1998.

Urban, O., Janous, D., Acosta, M., Czerny, R., Markova, I., Navrátil, M., Pavelka, M., Pokorný, R., Šprtová, M., Zhang, R., Špunda, V., Grace, J., and Marek, M.: Ecophysiological controls over the net ecosystem exchange of mountain spruce stand, Comparison of the response in direct vs. diffuse solar radiation, Glob. Change Biol., 13, 157-168, 2007. 
Urban, O., Klem, K., Ač, A., Havránková, K., Holišová, P., Navrátil, M., Zitová, M., Kozlová, K., Pokorný, R., Šprtová, M., Tomášková, I., Špunda, V., and Grace, J.: Impact of clear and cloudy sky conditions on the vertical distribution of photosynthetic $\mathrm{CO}_{2}$ uptake within a spruce canopy, Funct. Ecol., 26, 46$55,2012$.

van Gardingen, P. R., Jackson, G. E., Hernandez-Daumas, S., Russell, G., and Sharp, L.: Leaf area index estimates obtained for clumped canopies using hemispherical photography, Agricul. Forest Meteorol., 94, 243-257, 1999.

Walker, P. and Maclellan, C.: Guidelines for Post Processing GER 1500 Spectral Data Files using a FSF Excel Template, NERC Field Spectroscopy Facility, http://fsf.nerc.ac.uk, 2009.
Wherley, B. G., Gardner, D. S., and Metzger, J. D.: Tall Fescue Photomorphogenesis as Influenced by Changes in the Spectral Composition and Light Intensity, Crop Sci., 45, 562-568, 2005.

Woodward, F. I.: Instruments for the Measurement of Photosynthetically Active Radiation and Red, Far-Red and Blue Light, J. Appl. Ecol., 20, 103-115, 1983.

Zeiger, E. and Field, C.: Photocontrol of the Functional Coupling between Photosynthesis and Stomatal Conductance in the Intact Leaf: Blue Light and Par-Dependent Photosystems in Guard Cells, Plant Physiol., 70, 370-375, 1982. 